\title{
DETERMINANTS OF DECISION AND PARTICIPATION OF RURAL YOUTH IN AGRICULTURAL PRODUCTION: A CASE STUDY OF YOUTH IN SOUTHERN REGION OF NIGERIA
}

\author{
Sunday B. Akpan, Inimfon V. Patrick, Samuel U. James, Damian I. Agom \\ Akwa Ibom State University, Obio-Akpa Campus, Nigeria \\ E-mail: brownsonakpan10@gmail.com
}

\begin{abstract}
Evidence of labour constrained in the rural area and increasing rural -urban migration as well as mounting youth unemployment in urban areas of the Southern of Nigeria drove our interest to analyze youth involvement in agricultural activities in the region. Specifically, the study determined factors that modeled rural youth decision and participation in agricultural activities in the Southern region of Nigeria. Data were collected from 300 youth spread across the rural areas of Akwa lbom State, one of the States in the region. Combinations of sampling methods were used to collect data for the study. Analytical tools used were descriptive and regression analysis (the Logit and Poisson regression). The Logit model estimates revealed that years of youth in social organization, access to ICT, nature of land ownership, and youth access to state owned agricultural programme were positive determined of decision of youth to engage in agricultural activities in the study area. On the contrary, male youth, years of formal education and marital status of youth were negative determinants. The Poisson estimates showed that, youth age, number of extension visit and years in social organization as well as purpose of farming were positive drivers of youth participation (numbers of hours spent in farm per day) in agricultural activities in the rural areas. On the other hand, years of formal education, farm income of previous farming season, land ownership and access to credit triggered youth participation negatively. Perceived constraints to youth involvement in agricultural activities were; insufficient initial capital, insufficient credit facility, poor storage facility, poor access to tractors and inadequate farm land among others. In order to increase youth involvement in agricultural activities in the rural areas, it is recommended that, stake holders should endeavor to provide storage facilities in the rural area to reduce the post-harvest losses. Communities in the rural area should support youth farmers through land donation. In addition government should empowered and strengthen youth groups or social capital formation in the rural Communities. State extension system should be strengthened to deliver more efficient services to youth farmers in the rural areas.
\end{abstract}

\section{KEY WORDS}

Youth, Rural development, Agricultural development, Agricultural diversification, Farm constraints.

The prolonged and sluggish nature of economic growth in most African countries has impacted adversely on the well-being of young Africans. Consequently, increase in poverty, unemployment, food imports, population, and relegated agricultural sector as well as inactive manufacturing sector and political instability among others prevailed in the region. However, young Africans, growing up in amidst of these crises have been particularly affected (Chigunta, 2002 and Akpabio, 2012). Evidences abound that young people in Africa are exposed to crime, militancy, sexual abuses, youth restiveness, political thuggery among other social vices (Alanana, 2003, Okafor, 2011, Anyadike et al., 2012). Youth involvement in these vices has been recently attributed to the high rate of unemployment resulting from inability of most African economies to generate sufficient job opportunities.

The problem of chronic youth unemployment is evident in Nigeria. For instance, in August 2007, the national youth unemployment summit was held. Currently, young people population's constitutes about $60 \%$ of the country's population (Nigeria Demographics Profile, 2015). According to the National Bureau of Statistics (2010), the national unemployment rates for Nigeria between 2000 and 2009 showed that the number of 
unemployed persons constituted $31.1 \%$ in $2000 ; 14.6 \%$ in $2007 ; 14.9 \%$ in 2008 and $19.7 \%$ in 2009. IN 2012, about 54\% of youth in Nigeria were unemployed (NBS, 2012 Report). Every year thousands of graduates are turn out from various educational institutions into the already congested labor market. Nigerian streets are littered with youth hawkers who ordinarily would have found gainful employment in some enterprises. In 2011, the national unemployment rate stood at $23.9 \%$, youth population alone constitutes more than $70 \%$ of the unemployed. With this scenario, the MDGs targeted on poverty reduction, reducing child and maternal mortality, increasing access to education, improved health and sanitation and protecting the environment cannot be achieved in 2015. A recent report by the World Bank clearly shows that Nigeria, like many other countries, is not on tract to meeting the goals in 2015. The indirect effect of increase youth unemployment has hindered the rapid growth of our economy. For instance, the current insurgence of the Boka Haram threat in the northern region is hampering the smooth running of the region's economy. The issue of militancy in the Niger Delta region is affecting foreign investment in the oil and gas sector of the country's economy. Crimes such as kidnapping, fraudsters and child abuse are mostly perpetuated by youth. These acts project the country's image negatively to the outside world.

However, many analysts believed that agricultural sector is naturally endowed with enormous potentials to absorb unemployed and surplus labour from other sectors of the economy (Akpan, 2010). Nigeria has vast natural resource potentials in the agricultural sector that could sufficiently engross the surplus or idle labour in her economy. The evergreen rainforest in the south and the rich savanna soil in the north as well as the rich water bodies that aligned the coastal states are capable of providing inexhaustible job opportunities for the idle and unemployed youth if these resources are harnessed appropriately in the country. However, the manner agricultural innovations are package to an extent modeled youth involvement in agricultural sector. The decision of youth to participate in agricultural production has a lot to do with the cultural, political, environmental and economic situation of a society. They are vulnerable to change either positive or negative. Hence, it becomes pertinent to identify those decision variables that could model youth behaviour towards agriculture. In an attempt to identify these variables, the study specifically determine factors that affect youth decision to involve in agricultural activities and those that model their actual participation.

Who are Youth? There is no generally agreed definition of the term 'youth'. Some school of thoughts considered it, as a period of transition from the dependency of childhood to adulthood's independence. This period is often characterized by sexual maturity, peak of strength and emotion as well as growing social and economic independency from parents and guidance. In developing societies; the period is often prolonged due to various types of social, economic and political uncertainties among others (Akpabio, 2012). Generally "Youth" as a social group is more often defined in terms of age. For this reason, the spectrum of youth has been variously defined as ranging the ages of 10 or 11 year (as in some traditional societies in Africa) to as high as 35 years in some countries like South Africa and Tanzania. In an attempts to 'standardize' the concept of youth, international organizations such as the United Nation and the Common Wealth of Nation defined youth as encompassing those between the 15 to 29 age group. The Population Reference Bureau (PRB) regards youth as those in the 10 to 24 years age group. The African Youth Charter promulgated in 2006 by the African Union considers that youth are people in the age range of 15 to 35 years of age. Finally the Nigeria's National Youth Development Policy encapsulates the youth as comprising of all young persons of age 18 to 35 years. In Nigeria, the tendency to extend the category of youth to 35 years and beyond seems to be a reflection of the emerging phenomenon of the prolonged period of youth dependency on the host. As noted by Abdullah (1998), this is a metaphor for Africa's poverty. This phenomenon is an indication of the inability of many young people in the country to be economically self-sustained which is as the result of the volatile economy situation in the country. Hence, for analytical purposes, and in corroboration with the definition of youth by the Nigeria's National Youth Development 
Policy, this study uses the age category 18 to 35 years as an acceptable definition of 'Youth' in Nigeria.

Justification for Involving Youth in Agricultural Production in Nigeria. The need to increase participation of youth population in agricultural activities is justified by the following facts: firstly, from researches, the current average age of a Nigerian farmer is around 55 years and by 2030 it is expected to rise to around 75 years (Akpan 2010 and Akpabio 2012). The situation is worsened by the fact that by 2030 , an estimated $50 \%$ more people will migrate to urban areas. It is doubtful if the present crop of ageing farmer can produced enough food to feed the anticipating population of 230 million people in 2030 . Secondly, the current level of youth unemployment in Nigeria is alarming. Youth unemployment incurred costs to the economy, society and their families (Ajaegbu, 2012 and CBN, 2014). Unemployment creates idleness and uselessness among young people and these can lead to increase crime, mental health problem, drug addiction and violence etc. Given the many opportunities available in food production and its subsidiary services, agriculture can play a significant role in reducing youth unemployment and by extension, unemployment generally in the region. Thirdly, the country's food import bill in 2007 to 2010 was $\$ 98$ trillion or $\$ 628$ billion. In 2010 alone, Nigeria spent $\$ 632$ billion on importation of wheat, 356 billion on importations of rice and $\mathrm{A} 217$ billion as well as $\mathrm{A} 97$ billion on fish import (CBN, 2014). If these trends continue in the nearest future the availability of food, certain economic activities and even economic development will be depending on exogenous factors outside our control. Therefore, there is an urgent need to reverse this trend through increase investment in agriculture. The youth population is strategic in this aspect given the level of technology applied in agricultural production in the country. In addition, the poor image of farmers and "agriculture" in general needs to be changed in Nigeria. The young people are the ideal agents for such anticipated change given their greater propensity and willingness to explore new ideas, concepts and technology which are all critical to changing the perception and practiced of agriculture in our domain. Agricultural activities at present are practiced in small scale basis and involve the use of less sophisticated technology in Nigeria. It is labour intensive thus requires considerable latent energy and capacity by farmers to execute most of the sector activities. In the face of the ageing farming population in the country, youth population represents the most appropriate group to target now given enormous energy embedded in them.

The present of vibrant and expanding markets for agricultural commodities (both primary and secondary commodities) in Nigeria offers tremendous opportunities for young Nigerians to earn good income from agricultural activities and break out from the viscous cycle of poverty. Furthermore, myriad of incentives created by government, NGO's, agricultural agencies are numerous in the agricultural sector in this country. Most of these incentives are untapped due to insufficient involvement of youth in the agricultural sector. Therefore increase involvement of youth in agriculture will exposed them to greater opportunities in both local and international environments than their contemporaries in other sectors.

Conceptual Framework used in the Study. This research work employed migration conceptual framework to explain various issues relating to youth involvement in Agricultural production in Nigeria. The decision to migrate involves both "push" and "pull" factors (Lewis, 1954; and Harris and Todaro, 1970). The 'push factors' include declining national resources; increasing cost of social amenities; loss of employment, oppressive religious, ethnic or political concerns; alienation from community; lack of opportunities for personal development, and/or effect of natural disaster. The 'pull factors' are the likelihood of better employment opportunities; good educational facilities; diversified marriage opportunities, and better recreational activities as well as sound economic environment (Bogue, 1969). Also, the Lewis migration model explains migration as a transfer of labor from labor-surplus sectors (rural areas) to labor deficit-sectors (urban areas) until a balance is reached. The Harris-Todaro model on the other hand, postulates that migrants assess various labor market opportunities available in the rural and urban sectors and choose the one that maximizes their expected gains. This model explains some of the deficiencies inherent in the 
Lewis model such as the rise in rural-urban migration in the context of rising urban unemployment. Overall, some empirical studies found that economic push factors (such as, the lack of rural credit, unemployment, and rural poverty) are most important; while others suggest that economic pull factors (such as, perception of high wages from urban employment) are dominant. Hence, this study rest on the fact that, youth migration (from the rural area/agricultural production) is a function of several factors such as pull factors, push factors and economic factors as well.

\section{LITERATURE REVIEW}

Few literature have delved into issues concerning youth involvement in agricultural production in Nigeria. For instance, Nnadi and Akwiwu (2008) examined determinants of youths' participation in agricultural production in Imo state, Nigeria. Data were generated from the three agricultural zones in the state. The empirical result revealed that, age, education, marital status, parent income, parent occupation, household size and youth dependent ratio were significant factors influencing youth participation in agricultural activities. Onemolease and Alakpa (2009) studied determinants of adoption decisions of rural youths in the Niger Delta region of Nigeria. They used 332 youth farmers sampled from 4 states in the region. Results showed that, contact with extension agents, income and gender were important determinants of young farmers' adoption of crop-related technologies. Income, stock size and gender have significant influence on the utilization of livestock-related technologies; while extension contact, stock size, income and gender played important role in the adoption of fishery technologies. In another research, Adekunle et al., (2009) examined the constraints to rural youth involvement in agricultural production in Kwara State, Nigeria. A total of one hundred and twenty (120) respondents were selected using a multi-stage cluster random sampling technique. The major constraints hindering youth participation in agriculture were identified as inadequate credit facility, lack of agricultural insurance, poor returns to agricultural investment, lack of basic farming knowledge and lack of access to tractors and other farm inputs. Also, Daudu et al., (2009) investigated the role of youths in agricultural development in Makurdi Local Government area (LGA) of Benue State. They identified the major problems that inhibited youth participation in agricultural activities to include; lack of commitment, lack of logistic support and insufficient land for farming. Earlier, Akpan (2010) identified factors that limit rural youth involvement in agricultural production in Nigeria. He divided these factors into economic, social and environmental factors. Economic factors included; inadequate credit facilities, low farming profit margins, lack of agricultural insurance, insufficient initial capital and production inputs. Social factors were; public perception about farming and parental influence to move out of agriculture. Environmental issues included; inadequate land, continuous poor harvests, and soil degradation. Akpan also examined reasons for rural youth involvement in non-farm activities but rather migrating to urban areas. He identified economic pull factors such as; perception of greater job opportunities due to the presence of industries or companies in cities. He also pinpointed economic push factors such as; poor physical infrastructure and social amenities in the rural areas; search for education and skills acquisition, and the absence of desirable job opportunities. Other factors include a general dislike of village life or expulsion from rural communities resulting from the commitment of an offense or crime. However, he stated that economic factors were the dominant reasons for rural youths increased involvement in non-farm activities and migrating to urban areas. Recently, Donye et al., (2012) analyzed youth's involvement in yam production in Wukari Local Government Area of Taraba State, Nigeria. A total of 90 youths involved in yam production were purposively selected and administered the questionnaires. The results revealed that majority of the respondents were within the age range of 31-40 years. Results of the regression analysis showed that farm size, marital status and income had significant relationships with the respondents' levels of yam production. In addition, Chikezie et al., (2012) determined factors influencing rural youth adoption of cassava recommended production practices in Onu-Imo Local Government Area of Imo State, Nigeria. Results 
showed that the level of adoption of the recommended cassava production practices was high. The determinants of adoption were: age, gender, marital status, education, farm size, household size, farming experience, amount of credit received, extension contact, and membership of cooperative societies, yield and income.

Most of the reviewed literature did not analyze specifically, determinants of youth decision to engage in agricultural production. Majority focused on agricultural technology adoption among youth famers. This study filled this gap, by empirically determining expanded factors (pull, push and economic based factors) that model youth decision and actual participation in agricultural production in Nigeria.

\section{RESEARCH METHODOLOGY}

The Study Area. The study was conducted in Akwa Ibom State. The state is located in the Southern region of Nigeria. It is located between latitudes $4^{\circ} 32^{1}$ and $5^{\circ} 33^{1}$ North and longitudes $7^{\circ} 25^{1}$ and $8^{\circ} 25^{1}$ east. It has a total land area of areas of $7,246 \mathrm{~km}^{2}$. The mean annual temperature of the state lies between $26^{\circ} \mathrm{C}$ and $29^{\circ} \mathrm{C}$ and average sunshine of about 1,450 hours per year. The mean annual rainfall ranges from $2,000 \mathrm{~mm}$ to $3,000 \mathrm{~mm}$, depending on the area. Naturally, maximum humidity is recorded in July while the minimum occurs in January. The state is bordered on the East by Cross River State, on the West by Rivers State and Abia State, and on the South by the Atlantic Ocean. Akwa Ibom State has a population of about 3,902,051 and a population density of 634 persons per square kilometers (National Population Commission, 2006). The state is basically an agrarian society where crops like maize, okra, waterleaf, cassava, yam and rice are cultivated in large quantities. Fishery including aquaculture; livestock and poultry businesses thrives well in the state. The state was picked among other states in the region because of it rich agricultural potentials. In addition, the state has well demarcated rural and urban areas. Furthermore, the geography of the state supports diverse agricultural activities, in addition to has been one of the most peaceful States in region and Nigeria. The state has thirty one (31) local government areas divided into three (3) senatorial/political districts. The three Senatorial districts are: Eket district which has twelve (12) local government areas; Uyo district has nine (9) local government areas and Ikot Ekpene district has ten (10) local government areas.

Data Source and Sampling Procedures. Primary data were used and respondents were youth. Combination of sampling methods was used to select respondents. Firstly, two local government areas with clearly distinct rural areas were purposively selected from each of the Senatorial district in the State. A total of six (6) local government areas were selected and used for data collection. In the second stage, five rural villages were randomly sampled from each of the six local government areas selected. A total of thirty rural villages were randomly sampled from the six local government areas used for data collection. In the third stage, ten (10) rural youth were randomly picked from each of the sampled village. Hence, a total of three hundred (300) rural youth were randomly sampled and used for data collection.

Empirical Model. A binary Logit model was used to identify significant factors that influence youth decision to engage in agricultural activities in the rural areas of the state. Implicitly, the specified model is shown in equation 1. The Logit Model which captures youth decision to participate in Farming is given below;

$$
\begin{gathered}
\mathrm{DEC}=\left(\frac{\mathrm{P}_{\mathrm{i}}}{1-\mathrm{P}_{\mathrm{i}}}\right)=\mathrm{Z}_{\mathrm{i}}=\beta_{0}+\beta_{1} \mathrm{AGE}+\beta_{2} \mathrm{GEN}+\beta_{3} \mathrm{EDU}++\beta_{4} \mathrm{MAR}+\beta_{5} \mathrm{SOC}+\beta_{6} \mathrm{ICT}+\beta_{7} \mathrm{LAO} \\
+\beta_{8} \mathrm{NSO}+\beta_{9} \mathrm{PPF}+\beta_{10} \mathrm{AAP}+\mathrm{U}_{\mathrm{i}} \ldots \ldots \ldots \ldots \ldots(1)
\end{gathered}
$$

The marginal effect of the Logit model measures instantaneous effect that a change in a particular explanatory variable has on the predicted probability (i.e. the likelihood that a youth in the rural area will choose to involve in agricultural activities or not); when the other covariates are kept fixed. They are obtained by computing the derivative of the conditional mean function with respect to explanatory variables. 


$$
\frac{\delta P_{i}}{\delta X_{i}}=\frac{E\{Y \mid X\}}{\delta X_{i}}=f\left(Z_{i}\right) \beta_{i}=f\left(X \beta_{i}\right) \beta_{i}
$$

Variables used in equation (1) are defined as follows:

$\mathrm{DEC}=$ Youth decision to participate in farming (dummy; 1 for yes and 0 for no)

$\mathrm{AGE}=$ Age of youth farmer (years)

GEN $=$ Gender of the farmer ( $1=$ Male, 0 otherwise $)$

$\mathrm{EDU}=$ Formal educational (years)

MAR = Marital status of a youth farmer ( 1 for married and 0 otherwise)

$\mathrm{SOC}=$ Membership of social group (number of years)

ICT = Access to ICT (Number of times youth farmer browse in a week)

$\mathrm{LAO}=$ Land tenure (dummy; 1 for owned land and 0 otherwise)

NSO $=$ Number of non-farm occupations

PPF $=$ Perceived price of fertilizer (dummy; 1 for high and 0 for normal)

AAP $=$ Youth access to state owned agricultural programme(s) (Number of programmes accessed)

$U=$ stochastic error term

$P_{i}=$ Probability to engage in agricultural activity

$\mathrm{Ln}=$ Natural logarithm function

To estimate the determinants of youth participation in agricultural activities. Numbers of hours a youth spent in his/her farm per day was used to measure the level of youth participation in agricultural activities. Hence, the number of hour(s) spent by any youth was discrete and takes only non-negative integer values; therefore the count-data model was specified. We chose a Poisson model (Santos Silva and Tenreyro, 2006). The model is explicitly shown as;

$$
U_{i}=E\{Y \mid X\}=\beta_{0}+\beta_{1} X_{1}+\cdots \beta_{n} X_{n}
$$

In Poisson model, the estimated coefficients correspond to semi-elasticity. Thus, coefficient estimates can be directly converted into marginal effects. For a continuous regressor $X_{i}$, the marginal effect is

$$
\frac{\delta U_{i}}{\delta X_{i}}=\frac{E\{Y \mid X\}}{\delta X_{i}}=\exp (X \beta) \beta_{i}=\beta_{i} U_{i}=\beta_{i} e^{\beta_{0}+\beta_{1} X_{1}+\beta_{2} X_{2}+\cdots \beta_{n} X_{n}}
$$

Implicitly, the Poisson regression model is shown below:

$$
\begin{gathered}
H R S=\emptyset_{0}+\emptyset_{1} A G E+\emptyset_{2} \mathrm{EDU}+\emptyset_{3} \mathrm{FIN}+\emptyset_{4} \mathrm{EXT}+\emptyset_{5} \mathrm{SOC}+\emptyset_{6} \mathrm{PUR}+\emptyset_{7} \mathrm{LAO}+\emptyset_{8} \mathrm{EXC}+ \\
\emptyset_{9} \mathrm{MAR}+\emptyset_{10} \mathrm{COS}+\mu_{\mathrm{i}} \ldots \ldots \ldots \ldots \ldots \ldots \ldots \ldots \ldots \ldots \ldots \ldots \ldots \ldots \ldots \ldots \ldots \ldots \ldots \ldots \ldots \ldots \ldots \ldots \ldots
\end{gathered}
$$

where:

$\mathrm{HRS}=$ Average number of hours spent in the farm in a day (discrete number)

$A G E=$ Age of a youth farmer (years)

$\mathrm{EDU}=$ Farmer's years of formal education

$\mathrm{FIN}=$ Last season farm income (A)

EXT $=$ Number of times in contact with an extension agent in the last farming season

$\mathrm{SOC}=$ Membership of social group (number of years)

PUR $=$ Purpose of farming ( 1 for commercial and 0 for family used)

$\mathrm{LAO}=$ Land tenure (dummy; 1 for owned land and 0 otherwise)

$E X C=$ Access to credit facilities (dummy 1 for access and 0 otherwise)

MAR = Marital status of farmer ( 1 for married and 0 otherwise)

$\mathrm{COS}=$ Average wage rate per day of hired labour $(\mathrm{A})$

Verification of Multicollinearity among Explanatory Variables used in the Analysis. Multicollinearity is among the commonest econometric problems of the cross sectional data 
analysis. This property of econometric was verified among explanatory variables to ensure the econometric stability and reliability of the regression estimates. The Variance Inflating Factor (VIF) was estimated and used to verify the presence of the multicollinearity among the explanatory variables. For VIF, the minimum possible value is 1.0; while value greater than 10 indicates a probably collinearity between the specified explanatory variable in question and the rest of the predictors in the model. According to Gujurati and Dawn, (2009), VIF is estimated using the formula stated below:

$$
\operatorname{VIF}_{j}=\left\{1 / 1-R_{j}^{2}\right\}
$$

Where $R_{j}^{2}$ represents the multiple correlation coefficient between one of the explanatory variable (designated as dependent variable) and the other specified explanatory variables in the study. The explicit model explaining the above mechanism is shown in equation 6 .

$$
\mathrm{X}_{\mathrm{j}}=\varphi_{0}+\varphi_{1} \mathrm{X}_{1}+\varphi_{2} \mathrm{X}_{2}+\cdots+\varphi_{\mathrm{n}} \mathrm{X}_{\mathrm{n}}+\varepsilon_{\mathrm{n}}
$$

\section{RESULT AND DISCUSSION}

The descriptive statistics of respondents (rural youth) is shown in Table 1. The result revealed an average age of about 30 years for youth in the study area. This means that, most youth in the rural areas are in their active age. An average period of formal education stood at 12.4 years. This connotes that, most youth in the rural area are educated, and there is high possibility of agricultural innovation adoption among them. About $53.30 \%$ of the respondents were male youth. The result also showed that, $79.70 \%$ of youth interviewed were married. Social capital formation among youth was low in the study area, as shown by an average of 2 years in social organizations. Only $10.70 \%$ of the rural youth sampled had accessed to ICT facilities. The result also showed that, about $40.30 \%$ of youth owned farm land. The rest acquired farm lands through lease and borrowed arrangement among others. About $74.30 \%$ of youth in the sampled area perceived that, fertilizer price was high. An average of 5 hours was spent daily in the farm by youth in the area. In addition, about $68.70 \%$ of youth engaged in agricultural activities for commercial purpose. Credit accessibility was very poor among youth in the area. The result revealed that, only $10.70 \%$ of the youth have access to credit facilities in the area. An average cost of hired labour stood at $\$ 1179.7$ in the study area. Previous farming season income stood at $\$ 16000$ on average; while extension agent visit average at 5 times per season.

Table 1 - Descriptive Statistics and socio-economic of youth in the Rural area of Southern Nigeria

\begin{tabular}{llllllllll}
\hline Variable & Min. & Max. & Mean & Std. Dev. & Variable & Min. & Max. & Mean & Std. Dev. \\
\hline DEC & 0.000 & 1.000 & 0.600 & 0.491 & APP & 0.000 & 5.000 & 0.759 & 1.121 \\
AGE & 19.000 & 35.000 & 30.500 & 6.273 & PPF & 0.000 & 1.000 & 0.743 & 0.438 \\
GEN & 0.000 & 1.000 & 0.583 & 0.494 & HRS & 0.000 & 14.000 & 5.380 & 3.086 \\
EDU & 0.000 & 16.000 & 12.433 & 4.223 & PUR & 0.000 & 1.000 & 0.687 & 0.465 \\
MAR & 0.000 & 1.000 & 0.797 & 0.403 & EXC & 0.000 & 1.000 & 0.107 & 0.309 \\
NSO & 0.000 & 2.000 & 0.447 & 0.531 & COS & 0.000 & 5000 & 1179.7 & 931.74 \\
SOC & 0.000 & 15.000 & 2.097 & 3.699 & FIN & 0.000 & $2.0 \mathrm{e}+06$ & $1.16 \mathrm{e}+05$ & $2.3 \mathrm{e}+05$ \\
ICT & 0.000 & 1.000 & 0.107 & 0.309 & EXT & 0.000 & 40.000 & 4.937 & 8.127 \\
LAO & 0.000 & 1.000 & 0.403 & 0.491 & & & & & \\
\hline
\end{tabular}

Source: Computed by authors, 2015. Note monetary value is expressed in Naira. Variables are as defined previously.

Test result to verify collinearity among specified explanatory variables used. Table 2 presents the Variance Inflating Factor (VIF) test results used to verify the status of the collinearity of explanatory variables used in the Logit and Poisson regression models. The result reveals that there was no serious or significant collinearity among explanatory variable in both models. 
Table 2 - The Variance Inflation factors (VIF) test result

\begin{tabular}{llll}
\hline Logit Model & & Poisson Model & \\
\hline Variable & VIF Estimate & Variable & VIF Estimate \\
AGE & 1.499 & AGE & 1.358 \\
GEN & 1.151 & EDU & 1.057 \\
EDU & 1.116 & FIN & 1.142 \\
MAR & 1.222 & EXT & 1.237 \\
SOC & 1.108 & SOC & 1.216 \\
ICT & 1.114 & PUR & 1.116 \\
LAO & 1.196 & LAO & 1.216 \\
NSO & 1.159 & EXC & 1.154 \\
PPF & 1.063 & MAR & 1.322 \\
APP & 1.270 & COS & 1.101 \\
\hline
\end{tabular}

Source: Computed by authors using gretl software.

For instance, the estimated VIF with respect to each variable was greater than unity, but less than the threshold value of 10 . The result suggests that, the explanatory variables specified in each model do not cluster together or exhibited multi-collinearity tendencies. This implies that the estimates of the two models to an appreciable extent are consistent and unbiased. In other words, the estimates of the two models are stable over time.

Factors that Modeled Youth Decision to involve in Agricultural Activities. The Logit model estimates used to identify determinants of youth decision to engage in agricultural activities is shown in Table 3. The diagnostic statistics of the estimated model revealed that, the log likelihood ratio of 55.173 is significant at $1 \%$ probability level. This indicates that the specified Logit model has a strong explanatory power. The pseudo $R^{2}$ of 0.1373 shows that about $13.73 \%$ of variability in the dependent variables or the decision to engage in agricultural activities is associated with the specified independent variables. This means that, more variables that could have affected the youth decision on involvement in agricultural activities in the study area were not included in the model.

Table 3 - Estimates of the Logit Model (Determinants of decision of Youth to engage in Agricultural Activities in Akwa Ibom State)

\begin{tabular}{|c|c|c|c|c|}
\hline Variable & Coefficient & Log odd coefficient & Marginal Effect & Z-values \\
\hline Constant & -1.296 & - & - & -1.460 \\
\hline AGE & 0.036 & 1.037 & 0.0085 & 1.461 \\
\hline GEN & -0.929 & 0.395 & -0.2082 & $-3.220^{* * *}$ \\
\hline EDU & -0.075 & 0.930 & -0.0168 & $-2.189^{* *}$ \\
\hline MAR & -0.913 & 0.401 & -0.1918 & $-2.424^{* *}$ \\
\hline SOC & 0.187 & 1.206 & 0.0435 & $3.824^{\star * *}$ \\
\hline ICT & 1.067 & 2.905 & 0.2104 & $2.054^{\star *}$ \\
\hline LAO & 0.549 & 1.731 & 0.1246 & $1.879^{\star}$ \\
\hline NSO & 0.148 & 1.159 & 0.0344 & 0.565 \\
\hline PPF & -0.043 & 0.958 & -0.0099 & -0.142 \\
\hline APP & 0.253 & 1.288 & 0.0586 & $1.730^{*}$ \\
\hline Log Likelihood & -173.398 & & Log ratio test (10) & $55.173^{* * *}$ \\
\hline McFadden $\mathrm{R}^{2}$ & 0.1373 & & Correct prediction & $65.90 \%$ \\
\hline Akaike Criterion & 368.796 & & Schwarz Criterion & 409. 501 \\
\hline
\end{tabular}

Source: Computed by authors using gretl software, data from field survey 2014 . Asterisks *, ** and ${ }^{* * *}$ represent significant levels at 10\%, 5\% and 1\% respectively. Variables are as defined in equation 1.

The empirical result revealed that the log odd coefficients of years of youth in social organization (SOC at $1 \%$ ), access to information and communications technology (ICT at $5 \%$ ), nature of land ownership (LAO at 10\%) and youth access to state owned agricultural programme (APP at 10\%) are positive and statistically significant with respect to the decision or probability of rural youth to engage in agricultural activities in the study area. The odd interpretation implies that for every unit increase of youth in a social organization (SOC), the odd in favour of youth decision to engage in agricultural activities increases by 1.206 or 
about $20.60 \%$ compared to a unit decrease of youth in a social organization. Similarly, increase in rural youth access to ICT facilities will result in about 2.905 or about $190.50 \%$ increase in the log odd in favour of youth decision to engage in agricultural activities compared to rural youth who do not have access to these facilities. Also, increase in youth access to state owned agricultural programme (APP) will lead to about 1.288 or $28.80 \%$ increase in the log odd in favour of youth decision to engage in agricultural activities compared to those who do not have access to these programmes. In a similar manner, about 1.731 or $73.10 \%$ increase in the log odd in favour of youth decision to engage in agricultural activities will occur for a unit increase in farm land owned by rural youth compared to those who do not owned farm lands. The result implies that increase in years of rural youth in a social organization (SOC), access to information and communications technology (ICT), land ownership (LAO) and access to state owned agricultural programme (APP); will increase their chances to make positive decision to engage in agricultural activities. In other words and using marginal effect results, a unit increase in SOC, ICT, LAO and APP among youth in the rural area of the state will increase the chance or probability of youth deciding to engage in agricultural activities by $0.0435,0.2104,0.1246$, and 0.0588 respectively.

The positive determinants of probability of rural youth to engage in agricultural activities satisfied a priori expectations. For instance, increase in years of membership of a social organization, promote social capital formation or networking among rural youth. Knowledge, ideas and experiences are shared among members of a social group. The social interaction among members helped to sustained their believed and confident in their occupations. Groups that shared the same occupation will easily encourage one another to stay put in their occupation. Also, increase in the use of ICT promotes social interaction among peers and between youth and experienced farmers as well other scientists. This result suggests that, increase use of ICT among rural youth will likely bring about resource use efficiency. This can be achieved through exchange of information and exposure of the youth to the latest technology in their fields of endeavor. In addition, increase ownership of farm land increases the probability of youth engagement in agricultural activities in the rural areas of the state. An area with a high population density will likely have constrained on agricultural land. This result perhaps suggests that, rural youth decision might be conditioned on the fact that, increase in land ownership among rural youth will likely reduced cost of production and probably expand farm's level profit. Similarly, increase in youth participation in the state owned agricultural programmes increases their probabilities of engagement in agricultural activities. This could likely be linked to incentives available or anticipated in such programmes. The result on membership of social organization and land ownership corroborate with the research report of Chikezie et al., (2012) and Onemolease and Alakpa (2009).

On the contrary, the marginal effect and the log odd coefficient of youth decision to engage in agricultural activities with respect to gender (GEN), education (EDU) and marital status (MAR) were negatively signed and statistically significant at $1 \%, 5 \%$ and $5 \%$ respectively. This means that as the number of male youth, years of formal education and marital status of youth in the rural areas of the state increase, the probability of youth engaging in agricultural activities reduces.

The result implies that a number increase in the rural male youth reduces the odd of increase involvement of youth in agricultural activities by 0.395 times or about $60.50 \%$ compared to a number increase in female youth. Alternatively, a number increase in the male youth increases the odds of reducing youth involvement in agriculture by $60.50 \%$. Using the marginal effect with respect to gender (GEN); the result implies that, a number increase in a male youth will result in 0.2082 reductions in the probability of rural youth to engage in agricultural activities. This result implies that, male youth are more vulnerable to rural-urban migration compared to the female counterpart. This result could be as the result of economic, social and environmental reasons as asserted by Akpan (2010).

Similarly, a unit increase in the formal education of youth reduces the odd of increase involvement of rural youth in agricultural activities by 0.930 times or about $7.00 \%$ compared 
to a reduction in years of formal education. Alternatively, a year increase in formal education of rural youth reduces the probability of decision to engage in agricultural activities by $1.68 \%$. The result suggests that, as youth acquired more years of formal education, they move out from the rural areas to search for greener pastures in the urban area. The finding indicates that, the absent of educational facilities in the rural areas is a serious push factor that militates against youth involvement in agricultural activities. As pointed out by Akpan (2010), wage differential between the rural and urban areas is one of the motivating factors for youth abandoning agricultural activities in the rural areas. This result is also in agreement with the research findings of Nnadi and Akwiwu (2008) and Chizekie et al., (2012).

In a similar manner, the relationship between marital status of a rural youth and the decision or probability to engage in agricultural activity is inversely related. That is, a number increase in the married youth reduces the log odd of Logit increase in youth decision to involve in agricultural activities in the rural area by 0.401 times or about $59.87 \%$ compared to, if they remain single. In another way, about $19.18 \%$ reduction in the probability of rural youth decision to involve in agricultural production occurs for a number increase in married youth in the study area. The likely reason for this result could be the difficulty of sustaining family in the rural area. This could also stem from low income from farming, lack of health institutions and infrastructures/amenities necessary for family up keeps. Similar finding has been reported by Chizekie et al., (2012).

Factors that determine number(s) of Hours Spent by Rural Youth farmers in Agricultural Activities. Factors that influence rural youth participation in agricultural activities were determined and are presented in Table 4. The diagnostic statistics shows that, the McFadden R-squared is about 0.058 , which implies that all the explanatory variables included in the model were able to explain about $6.00 \%$ variability in the number(s) of hours spent by rural youth farmers in the study area. This result justified the fact that several economic, environmental and social factors that inhibited youth participation in agricultural activities in the study area were not included in the specified model. This however explains the complexity involved in studying youth demand in most developing economies. The value of the normality test attested to the normal distribution of the error term generated in the Poisson regression. The Chi square test $\left(16.559^{\star * *}\right)$ is statistically significant at $1 \%$ probability level, implying that the estimated Poisson regression has a goodness of fit.

Table 4 - Poisson Estimates on Determinants of Participation of Youth in Agricultural Activities in Akwa lbom State

\begin{tabular}{|c|c|c|c|c|}
\hline Variable & Coefficient & Standard Error & Marginal effect & Z-values \\
\hline Constant & 1.2680 & 0.1736 & - & $7.307^{* \star \star}$ \\
\hline AGE & 0.0114 & 0.0045 & 0.0439 & $2.519^{\star *}$ \\
\hline EDU & -0.0144 & 0.0059 & -0.0555 & $-2.423^{* *}$ \\
\hline FIN & $-2.9089 e-07$ & $1.304 \mathrm{e}-07$ & $-1.1216 \mathrm{e}-06$ & $-2.231^{* *}$ \\
\hline EXT & 0.0209 & 0.0029 & 0.0806 & $7.143^{\star \star \star}$ \\
\hline SOC & 0.0125 & 0.0070 & 0.0482 & $1.785^{\star}$ \\
\hline PUR & 0.2119 & 0.0597 & 0.8171 & $3.549^{\star \star *}$ \\
\hline LAO & -0.0973 & 0.0563 & -0.3752 & $-1.730^{*}$ \\
\hline EXC & -0.1321 & 0.0527 & -0.5094 & $-2.506^{\star \star}$ \\
\hline MAR & 0.0290 & 0.0702 & 0.1118 & 0.4133 \\
\hline $\cos$ & $-2.9815 e-05$ & $2.868 \mathrm{e}-05$ & $-1.1496 e-04$ & -1.0390 \\
\hline Log Likelihood & -745.482 & & Normality test & $11.426^{\star \star *}$ \\
\hline McFadden R2 & 0.0575 & & Schwarz criterion & 1553.706 \\
\hline Akaike Criterion & 1512.965 & & Chi-square (1) & $16.559^{\star * \star}$ \\
\hline
\end{tabular}

Source: Computed by authors using Stata software, data from field survey 2014. Asterisks *, ${ }^{* *}$ and ${ }^{* * *}$ represent significant levels at 10\%, 5\% and 1\% respectively. Variables are as defined in equation 2.

The empirical result showed that, the age (AGE at $5 \%$ ) of youth in the rural area has a positive relationship with the number of hours spent per day in agricultural activities. The result implies that, a unit increase in the youth age will lead to about $4.39 \%$ increase in the hours spent per day in agricultural activity. This means that, agricultural participation among 
youth in the study area increases with increase in age of the youth. Similarly, number of times a youth farmer has contact with extension agent(s) positively influence hours spent per day in agricultural activities. For instance, a unit increase in extension agent visit will result in $8.06 \%$ (EXT at 1\% significant level) increase in hours spent in agricultural activities. This result suggests that, a strong extension system can encourage youth participation in agricultural activities in the rural area. In the same manner, membership in a social organization promoted youth participation in agricultural activities positively. Result revealed that, one year increase in a social group by youth in the rural area will result in $4.82 \%$ (SOC at $10 \%$ increase in the number of hours spent per day by them in agricultural activities. This result showed the important of social capital formation among youth in the rural areas.

The purpose of youth engagement in agricultural activities also has a strong positive correlation with the number of hours spent by them in agricultural activities in the rural area. That is, for every commercial oriented purpose of youth engagement in agricultural activities, there is $81.71 \%$ (PUR at $1 \%$ level) increase in the number of hours spent per day in the agricultural activities. The result satisfies the a priori expectation, as commercial oriented farmer is expected to spent much hours in his/her farming activities.

On the other hand, the coefficient of youth education (EDU at 5\%), farm income of previous farming season (FIN at 5\%), land ownership (LAO at 10\%) and access to credit (EXC at 5\%) have significant inverse relationship with the number of hours spent per day by youth in agricultural activities in the rural area.

The result for education suggests that, increase in years of formal education will lead to about $5.55 \%$ reduction in the average hours spent per day by rural youth in agricultural activities. This means that, increase in years of formal education of rural youth will exposed them to better opportunities and high wage rate jobs in urban areas and this will forced them to abandon agricultural activities in the rural areas. This result corroborates with the research findings of Chikezie et al (2012) and Akpan (2010).

Similarly, a unit increase in the previous season farm income of youth reduces the number of hours spent by rural youth at $0.0000112 \%$ per day. This means that, as the previous farm income of youth increases, current hours spent per day in agricultural activities reduces. The finding pinpointed to the problem of poor storage and or processing facilities in the rural areas of the State. As a result of poor facilities, youth farmers might decide to postponed or reduce production in the current year to avoid post-harvest losses. The issue of agricultural diversification, temporary rural - urban migration, multiple jobs and part time business among others could also explained this phenomenon in rural youth. Onemolease and Alakpa (2009) have reported similar result.

The result also revealed that, access to credit facilities has a negative association with hour spent per day by rural youth in agricultural activities. This connotes that, a unit increase in access to credit facility by youth reduces the number of hours spent per day in agricultural activity by $50.94 \%$. This means that there is an increase tendency of agricultural diversification when access to credit increases among rural youth. The result suggest that most rural youth perceived agricultural production is not profitable enough or yield fast income as compared to non-agro based businesses. Another possible reason for the result could be conditions attached to such credit facility; this might force youth to diversified investment in order to avoid risk inherent in agricultural activities.

Perceived Constraints to Youth involvement in Agricultural Activities in Akwa lbom State, Nigeria. Responses of rural youth concerning factors militating against their involvement in agricultural activities were analyzed and presented in Table 5. Qualitative tools such as percentages and ranking were employed to identify the most important constraints. Results revealed that, insufficient initial capital $(88.41 \%)$ is the most important perceived constraint faced by rural youth in the State. Inadequate credit facility $(86.59 \%)$ and poor storage facilities (85.98\%) also constitute perceived hindrances to youth involvement in agricultural production in the State. 
Table 5 - Constraints to Youth Engagement in Agricultural Activities in Akwa Ibom State, Nigeria

\begin{tabular}{lll}
\hline Constraint & Percentage & Ranking \\
\hline Insufficient initial capital & 88.41 & 1 \\
Inadequate credit facility & 86.59 & 2 \\
Poor storage facilities & 85.98 & 3 \\
Insufficient access to tractors \& other farm inputs & 84.76 & 4 \\
Insufficient of land & 80.49 & 5 \\
Soil degradation & 75.00 & 6 \\
No agricultural insurance & 65.24 & 7 \\
Poor returns to investment & 59.15 & 8 \\
Farmers are not respected & 56.71 & 9 \\
No ready market & 55.49 & 10 \\
People perception & 55.49 & 10 \\
Continuous poor harvest & 51.22 & 11 \\
It is energy-demanding & 49.39 & 12 \\
Poor basic farming knowledge & 43.90 & 13 \\
Non - lucrativeness of agriculture & 37.80 & 14 \\
\hline
\end{tabular}

Source: Computed by authors, 2015.

The youth also perceived that, insufficient access to tractors \& other farm inputs $(84.76 \%)$, insufficient land for farming $(80.49 \%)$ and soil degradation problem $(75.00 \%)$ as well as absent of agricultural insurance $(65.24 \%)$ are other significant deterrent to rural youth involvement in agricultural activities in the State. In addition, the study identified poor returns to farming investment (59.15\%) and the notion that farmers are not respected $(56.71 \%)$ as mild constraints to youth involvement in agricultural activities in the rural areas of Akwa lbom State. Other less important perceived constraints identified included; no ready market (55.49\%), People perception about farming in the rural areas (55.49\%) and continuous poor harvest $(51.22 \%)$. However, the study asserted that, the opinion that farming is energydemanding (49.39\%) and the existence of poor basic farming knowledge $(43.90 \%)$ as well as the perception that farming is not lucrative $(37.80 \%)$ were not upheld by majority of rural youth in the State.

\section{CONCLUSION AND RECOMMENDATIONS}

Youth involvement in agricultural activities must be seen as one reliable way of managing food insecurity, social unrest, crime, drug abuse and combating extreme poverty in Nigeria. Though majority of our youth viewed agricultural sector has been unattractive and lacking the necessary economic incentives to enhance well-being; however this perception is false owing to the fact that Nigeria is truly an agrarian society. The emergence of the oil sector relegated agricultural sector to the trough. From history, Nigerians well-being was better before oil exploitation when compared to the available statistics now. Therefore any attempt to revitalize agricultural sector is a direct effort to improve Nigerians well-being. Youth involvement in agricultural activities is seen as one of the most reliable tools to rejuvenate agricultural sector in the country. This is due to their high resilience, latent energy and adaptability in addition to the current structure of the sector. To stimulate youth involvement in agricultural activities will require a holistic policy package that will involves all stake holders in the country. Youth specific characteristics and environmental issues must play a prominent role in such policy framework. On summary, the study has discovered that, youth year(s) in social organization(s), access to information and communications technology, nature of land ownership, and youth access to state owned agricultural programme are positive and significant drivers of youth decision or probability to involve in agricultural activities in the rural area. On the other hand, rural youth decision to engage in agricultural activities is negatively affected by gender composition of rural youth, years of formal education and their marital status. In addition, the rural youth participation in agricultural activities is mostly influenced by the age composition of the youth; the number of extension visits per farming season; purpose of youth involvement in agricultural activities 
and the magnitude of social capital formation among them. The antagonistic factors to rural youth participation in agricultural activities include; increase in acquisition of formal education, increase access to agricultural credit, increase in the previous farm income and increase in self-owned farm land among youth. Some of the perceived constraints of youth participation in agricultural activities were: insufficient initial capital, inadequate credit facility, poor storage facilities, insufficient access to tractors and other farm inputs, insufficient land for farming, and soil degradation problem as well as absent of agricultural insurance.

Based on findings of the research, the following recommendations were proposed:

Financial Enhancement Based Recommendations:

$>$ Provision of storage facilities in the rural area to reduce the post-harvest losses often experienced by farmers (this will enhanced farmer's revenue).

$>$ Instituting agricultural insurance for youth farmers will guarantee against production risks especially on issue of climate change and diseases.

$>$ Facilitating greater market opportunities for farm produce through organized linkage with potential buyers.

Social and Educational based Recommendations:

$>$ Communal support through land donation to youth farmers

$>$ Empowering and strengthening youth groups/social capital formation in the rural Communities. Emphasis should include internet social media.

$>$ Enterprise development training particularly for rural youth in value added activities such as food processing and packaging.

$>$ Regular creation of workshops, training courses seminars and demonstration farms in the rural areas of the state. These will motivate those youth already in agriculture and spur up interests of those outside agriculture to come in.

$>$ Building of standard schools in the rural areas and also ensuring adequate incentives to teachers in the rural areas. This will enhanced the quality of teaching and curtailed youth migration from the rural to urban areas.

$>$ Provision of electricity, health centers, recreational centers and modern water supply in the rural areas are reliable and sure means of settling youth in the rural areas.

Government Specific Intervention Strategies/Recommendations:

$>$ One critical role of government needed to achieve increase in agricultural productivity through increase in youth involvement in agriculture in the country is the issue of stable political environment. Stable political environment will generate sound policy framework good policy institutions and workable policies in the agricultural sector.

$>$ Government as a matter of policy should motivate successful youth farmers through merit awards.

$>$ The agricultural extension system in the State should be strengthened to continue to impact positively on rural youth famers.

\section{REFERENCES}

1. Abdullah, Ibrahim (1998), 'Bush Path to Destruction: the Origin and Character of the Revolutionary United Front/Sierra Leone', Journal of Modern African Studies, 36, 2, pp. $203-234$.

2. Adekunle, O., Adefalu, L., Oladipo, F., Adisa, R., and Fatoye, A. (2009). Constraints to Youths' involvement in Agricultural Production in Kwara State, Nigeria. Journal of Agricultural Extension Vol. 13 (1) June, 2009; 102-108.

3. Ajaegbu, O. O., (2012). Rising Youth Unemployment and Violent Crime in Nigeria. American Journal of Social Issues \& Humanities; Vol.2(5) pp.315 -321. ISSN: 2276 6928. http://www.ajsih.org.

4. Akpabio, I. A. (2012). Youth employment and agricultural Development: the inextricable Siamese twins. $34^{\text {th }}$ Inaugural lecture Series of the University of Uyo, Nigeria.

5. Akpan, S. B., (2010). Encouraging Youth Involvement in Agricultural Production and Processing in Nigeria. Policy Note No. 29: International Food Policy Research Institute, Washington, D.C. 
6. Alanana, O. O. (2003). Youth unemployment in Nigeria: some implications for the third Millennium. Global Journal of Social Sciences: 2 (1): 21-26.

7. Anyadike Nkechi, Emeh Ikechukwu E. J. and Ukah Finian O. (2012). Entrepreneurship development and employment generation in Nigeria: Problems and prospects. Universal Journal of Education and General Studies Vol. 1(4) pp. 88-102

8. Bogue, D., 1969. Principles of Demography, Wiley, New York.

9. Central Bank of Nigeria Website (2014). Retrieved on the $5^{\text {th }}$ of July, 2015. (http://www.cenbank.org/).

10. Chigunta, F. (2002): "The Socio-economic Situation of Youths in Africa: Problems, Prospects and Options." A Paper Presented at the Youth Employment Summit, Alexandria, Egypt, pp. 1-13.

11. Chikezie N. P., Omokore D. F., Akpoko J. G. and Chikaire J. (2012). Factors Influencing Rural Youth Adoption of Cassava Recommended Production Practices in Onu-Imo Local Government Area of Imo State, Nigeria.

12. Daudu, S; Okwoche, V. A. and Adegboye, O. G. (2009). Role of Youths in Agricultural Development in Makurdi Local Government Area of Benue State. Journal of Agricultural Extension. Vol. 13 (2); pp. 107 -112.

13. Donye, A., Gwary, M., Nuhu, H. and Zhintswen, A. (2012). Assessment of youth involvement in yam production in Wukari local Government area of Taraba State, Nigeria. Agriculture and Bology Journal of North America; ISSN Print: 2151-7517, ISSN Online: 2151-7525, doi:10.5251/abjna.2012.3.8.311.317 (C) 2012, ScienceHuß, http://www.scihub.org/ABJNA.

14. Gujarat, N. D., Dawn, C. P. (2009). Basic Econometric. McGraw-Hill International Edition. Singapore.

15. Harris, J. R. and M. P. Todaro (1970). "Migration, unemployment and development: A two sector analysis.

16. Lewis, W., 1954. Economic development with unlimited supplies of labour. The Manchester school, vol. 22, no. 2, Pp. 139-191.

17. National Bureau of Statistics (NBS), Publication 2010. Retrieved from http://www.nigerianstat.gov.ng/. on the $5^{\text {th }}$ of July, 2015.

18. National Population Commission (2006). Publications. Retrieved from http://www.qtsnigeria.com. On the $5^{\text {th }}$ of July, 2015.

19. Nigeria Demographics Profile 2015. Extracted from http://www.indexmundi.com/nigeria/demographics_profile.html on the 5th of July, 2015.

20. Nnadi, F., and Akwiwu C. (2008). Determinants of youths' participation in Rural Agriculture in Imo State, Nigeria. journal of Applied Sciences; 8(2); 328 - 333.

21. Okafor, E. E., (2011). Youth Unemployment and Implications for Stability of Democracy in Nigeria. Journal of Sustainable Development in Africa (Volume 13, No.1, 2011, PP 358-373.

22. Onemolease, E., and Alakpa, S. (2009). Determinants of Adoption Decisions of Rural Youths in the Niger Delta Region of Nigeria. J. Soc. Sci, 20(1): 61-66.

23. Santos Silva J. M. C. and Tenreyro S., (2006), "The Log of Gravity," The Review of Economics and Statistics, MIT Press, vol. 88(4), pages 641-658, 09. 